\title{
ConCEPTUAL MOdel FOR EleCtRonic ClinicAL RECORD INFORMATION SYSTEM
}

\author{
Saima Nisar ${ }^{1}$ and Abas B Said ${ }^{2}$ \\ ${ }^{1,2}$ Department of Computer \& Information Sciences, \\ Universiti Teknologi PETRONAS, \\ Bandar Seri Iskandar, 31750 Tronoh, Perak, Malaysia. \\ E-mail: saimaanisar@gmail.com
}

\begin{abstract}
This study is drawn from an ongoing, large-scale project of implementing Electronic Clinical Record (ECR). The overall aim in this study is to develop a deeper understanding of the socio-technical aspects of the complexities and challenges emerging from the implementation of the ECR, and in particular to study how to manage a gradual transition to digital record. We have proposed ECR conceptual model. The end result of our research was a collection of ideas / surveys, and field work that clinical institutions and medical informatics must consider to ensure that patients and clinics do not lose long-term access to ECR and technology continually progress. Results of our study identified the need for more research in this particular area as no definitive solution to long-term access to electronic clinical records was revealed. Additionally, the research findings highlighted the fact that a few medical institutions may actually be concerned about long-term access to electronic records.
\end{abstract}

\section{KEYWORDS}

ECR - Model - Information System - Digital Record - Technology

\section{INTRODUCTION}

Information and Communication Technology (ICT) has improved remarkable change in the provision and management of intelligent healthcare services

\subsection{Information Technology in Healthcare}

Information technology (IT) has the capability to develop the value, security, and performance of health care. Healthcare is a huge and growing industry that is experience key alteration in its information technology base [1]. Clinics are in a healthcare industry and they would get enormous advantage by adopting IT applications, ranging from medical to administration systems. Accurate and proper adoption of IT can drastically influence the value and performance of medical services provided by a Clinic [2]. These factors will significantly affect the further progress of information processing in healthcare within the near future: the development of the population, medical advances, and advances in informatics [3]. The proceeding technologies and terms are usually involved in discussion s of IT in healthcare:

DOI : $10.5121 /$ ijist.2012.2102 
- Electronic Health Record (EHR)

- Electronic Medical Record (EMR)

- Computerized Provider Order Entry (COPE)

- Clinical Decision Support System (CDSS)

- Picture Archiving and Communications System (PACS)

- Bar Coding

- Radio Frequency Identification (RFID)

- Electronic Materials Management (EMM)

- Interoperability

\subsection{Electronic Clinical Record}

An Electronic Clinical Record (ECR) is an electronic way for storing Clinical Information System (CIS). Most of the ECR duplicates the formation that is used in the Paper-based Record (PR), and it accumulates all the information that is related for the treatment and nursing of a patient. Among others, the record includes doctors' notes and nurses' notes concerning the ongoing treatment. Various studies have shown that PR can not sufficiently maintain the work of patient care in well-organized manner [4].The ECR includes both CIS: such as diagnoses, allergies, and medicines; and demographic information, such as: Personal Information (PI), for non-clinical use. It includes information that is used in various areas for different purposes. Doctors can instance, use the ECR for diagnostic and therapeutic decisions [5].

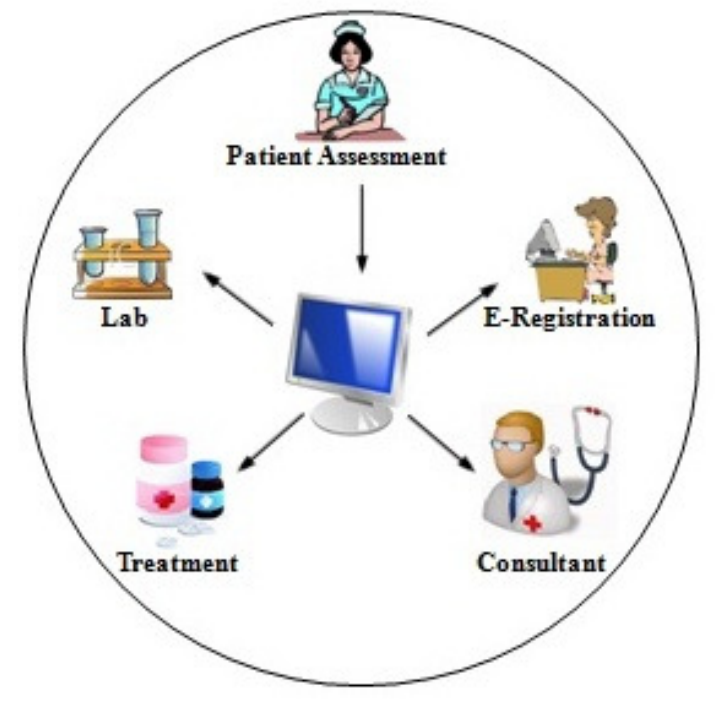

Figure .1 Application of Electronic Clinical Record

\subsection{Visions and Challenges of Electronic Clinical Record:}

The idea of computerized record that contains information as recorded was introduced in the 1960's and 1970's [6], [7]. An ECR is supposed to authorize essential development to the healthcare work practice [8]. It is not our view to reveal all of them, but slightly to point out the significant ones. Substitute PR with ECRs will significantly boost the process information is collect, organize, extend, and utilize. Until now, the several of healthcare records were printed on paper and kept in a PR folder [9]. The ECR personnel do not want to waste a long time in 
struggle to write down the PR in the entire clinic while it is continuously offered in the electronic format. The ECR open up innovative possibility while it permit various people to sight the same record concurrently from different computers, also to recover the most updated information.

\subsection{Clinical Information Systems}

A Clinical Information System (CIS) is a computer based system that replaces the Paper-based Record (PR), it organize, design, store, collect, manipulate, double checks all medical information, and make available clinical information important to the healthcare delivery process. Clinical information systems (CIS) could drive progress in health care in the $21^{\text {st }}$ century, it is a collection of various information technology applications that provides a centralized repository of information related to patient care across distributed locations [10].

\subsection{Benefits of Clinical Information Systems}

Clinical information systems provide major benefits in direct support of patient care. They are a vast improvement over the paper record in reporting, organizing, and locating clinical information.

- CIS can provide convenient access to clinical record at all points of care.

- Information captured is well organized, legible and timely manner.

- CIS improve prescription drug dosing, and reduce the adverse drug interactions and while promoting more appropriate pharmaceutical utilization.

- In emergency doctors has immediate access to complete patient case history.

- Doctors can send prescriptions directly to the pharmacy, where patient can pick up.

\subsection{Statement of the Problem}

Over the past years the adoption of electronic record technology in the healthcare has been the focus of many studies.

The problem stated in this paper is that, the several of healthcare records are documented on paper and kept in a PR folder. Paper record can be easily lost, misplaced, or are often illegible due to any accident or any mismanagement, administration among clinicians is poor in the manual healthcare system. Patients are being admitted unnecessarily stays in the clinic, multiple tests are being ordered, and adverse drug reactions are happening because clinicians are not aware of drugs prescribed. Clinic staff and patients are receiving conflicting treatment information and advice from doctor.

Medical errors are leading causes of death patient are died because of administration of the wrong medicine to wrong patient. Clinical administrators are realigning business strategies to make sure they have the proper healthcare systems in place to store the amounts of patient-related data and information. Until now, there is no appropriate answer detailing the way in which clinics will assurance the availability of a patient's medical record once it is digital. The use of electronic health record technology would eliminate many of these issues and lead to major improvements in the health and safety of patient care.

In order to reduce clinical errors, we provide more effective methods of communicating and sharing information among clinicians, and better manage patient medical records. We need to embrace Information and Communication Technology (ICT) in healthcare. We will introduce a solution, which is presently involves transformation of the information from the Paper-based 
International Journal of Information Sciences and Techniques (IJIST) Vol.2, No.1, January 2012

Record (PR) to an Electronic Clinical Record (ECR). Particularly, electronic healthcare records would be placed in the patient's charge to manage over their lifetime information in record. The implementation of ECR is broadly considered an essential component of future healthcare delivery. ECR is seen as key to the vital inter-operability required for healthcare efficiency, effectiveness and safety; and quality needs [11], [12]. A new healthcare system model is necessary to offer proper facilities for a patient. Due to this, research focuses on addressing the healthcare issues. The new method should be user friendly, provide a higher facilities and an efficient clinical record. This research plans to study some well-know related work.

\subsection{Research Objectives}

The aim of this research is to propose a new model that supports the Electronic Clinic Record (ECR) application. It will study essential related work to examine the available healthcare records outcome and drawbacks. It will propose new model to improve the clinical systems. The objective of this research is to ensure sufficient in-depth knowledge of the challenges confronting service delivery in health, especially in the healthcare sector; and a grasp of how the underlying ICT infrastructure and an ECR might be expected to assist in meeting these challenges. In this research the specific objectives are as follows: To know detail understanding of electronic healthcare record and do detail literature review. To propose a new electronic clinic record model that is able to fulfil the clinical requirements. To do detail survey of related clinic and apply our propose model to improve electronic healthcare record

\section{REVIEW OF RELATED LITERATURE:}

Information and Communication Technology (ICT) has become the information resource of both selection and requirement and has thus motivated from the margin of healthcare. Quick advances in ICT with reduced costs, improved reliability and better robustness are enabling a new wave of transform in how and where healthcare can be delivered.

Many researchers consider that the electronic record will considerably modify healthcare, rather than merely replacing the Paper-based Record (PR). This alteration allows data to be used for a wide variety of purposes ranging from direct patient care, decision maintain, quality promise, scientific research, and management of healthcare facilities [13]. In their review of the medical related work, the use of electronic medical records is linked with enhanced surrogate outpatient care outcomes. [14], [15]

This research will discuss the fundamental background of the related healthcare records. This research also identifies the importance of the healthcare records through electronic way. This proposal will also study a general discussion of related research work for healthcare real-time applications. There are a number of healthcare ways introduced to meet the above requirements. In literature review describe the manual and electronic healthcare records, advantages, disadvantages, and challenges.

\subsection{Electronic Health Records}

The Electronic Health Record (EHR) is a longitudinal electronic record of patient health information created by one or more encounter in any care delivery conditions [16], Included in this information are patient vital signs, problems, past medical history, demographics, progress notes, medications, laboratory data, immunizations, and radiology reports. The EHR has the aptitude to form a full record of a patient encounter, as well as supporting other care-related activities directly or indirectly via interface including evidence-based decision support, quality management, and outcomes reporting [17], [18]. 
The drawbacks of the HER are with the complicated, focus on big hospitals and consider as a big commercial business. An EHR is actually multiple organizations within one. Many EHRs have multiple healthcare facilities, such as affiliated hospitals and, numerous specialties diagnostic and treatment centres, laboratories associated with training and research, and complex business operations to manage all of these complicated components.

\subsection{Electronic Patient Records}

There has been a growing attention in the area of Electronic Patient Records (EPR) and more and more hospitals all over the world attempt to keep their patients' records electronically. The implementation of EPR has become a main concern in the healthcare business, as it is a key issue to the healthcare quality development [19].

Today, despite the immense investment in EPR systems in hospitals, these systems are not used by the clinical staff in most hospitals. The main drawbacks of EPR are limited for hospitals.

\subsection{Electronic medical record}

The meaning of electronic medical record (EMR) is that the electronic record of health associated information on an individual that is created, collect, managed, and consulted by certified medical and staff from a single organization who are involved in the individual's health and care. By these definitions, it can be understand that EHR is more comprehensive view of patient's overall health state. An EHR document is shared across different health providers. EMR is a record regarding the only diagnosis or treatment and mainly linked with a single health office [20]. In addition, it cannot be said as full in all phase because EMR deals with information of a single patient of a clinic. In case of EHR, it controls the latest data of patient's health condition. Thus, it is more helpful in the treatment of patient.

Now, there are a number of problems occurred in the patient monitoring system in both local and foreign hospitals such as: lost of information when data are recorded automatically from the hardware patient monitoring system into the database without involvement of the physician, blur images taken by the system which gave wrong or inaccurate information to doctors in emergency cases (usually occurred in mobile system), patients' medical records are written on papers and no backup for the records in case of information lost, and large number of patients and less number of staff in the hospital lead to difficulties in recording all the medical information properly [21].

\subsection{Technology Acceptance Model}

Technology acceptance model (TAM) is an adaptation of the Theory of Reasoned Action (TRA) to the field of Information Systems (IS) that models how users come to accept and use a technology. TAM was proposed by Davis in 1989 as a measure that could explain and predict system use. Davis suggests in this model that when users are presented with a new technology, a number of factors influence their decision about how and when they will use it. This model proposed two specific variables which can be used to measure users acceptance of new IS which were perceived usefulness and perceived ease of use.

Perceived usefulness is defined as "the degree to which a person believes that using a particular system would enhance his or her job performance". Perceived ease of use was in turn defined as "the degree to which a person believes that using a particular system would be free of effort" [22]. 


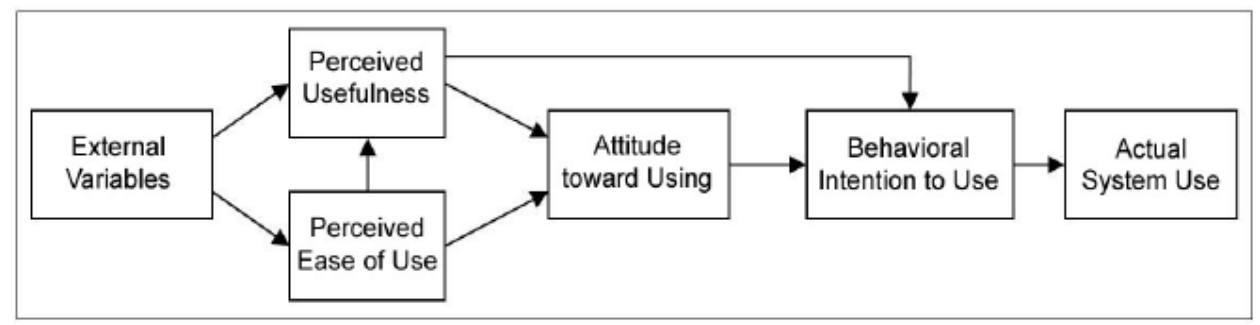

Figure 2. Technology Acceptance Model (Davis, 1989)

\subsection{Actor Network Theory}

Actor Network Theory (ANT) is used for understanding Information Systems (IS). ANT deals with the social-technical divide by denying that purely technical or purely social relations are possible. Information Infrastructures (IIs) are large integrated collections of information systems. When viewing IIs through the lens of this theory, they can be seen as large actor-networks, including existing technologies, standardization bodies, software vendors, users and so forth. According to ANT, these actors interact and affect each other continuously.

Table 1. Related Work

\begin{tabular}{|l|l|l|l|}
\hline Year & \multicolumn{1}{|c|}{ Authors } & \multicolumn{1}{|c|}{ Model } & \multicolumn{1}{|c|}{ Results } \\
\hline 2004 & Nina Boulus & Actor Network Theory (ANT) & $\begin{array}{l}\text { Understanding of Socio- } \\
\text { technical aspects }\end{array}$ \\
\hline 2008 & $\begin{array}{l}\text { Mahbod } \\
\text { Hamidfar }\end{array}$ & $\begin{array}{l}\text { Unified Theory of Acceptance } \\
\text { and Use of Technology } \\
\text { (UTAUT) }\end{array}$ & $\begin{array}{l}\text { Stronger social influence on } \\
\text { Behaviour (Women) }\end{array}$ \\
\hline 2008 & $\begin{array}{l}\text { Mary Elizabeth } \\
\text { Morton }\end{array}$ & $\begin{array}{l}\text { Diffusion of Innovations } \\
\text { (DOI), and Technology } \\
\text { Acceptance Model (TAM) }\end{array}$ & $\begin{array}{l}\text { Impact of socio-technical } \\
\text { factors on Physician } \\
\text { attitudes }\end{array}$ \\
\hline 2008 & $\begin{array}{l}\text { N. Azliza, A. } \\
\text { Mohd Yunus }\end{array}$ & $\begin{array}{l}\text { Clinical Microsystems } \\
\text { Hameed }\end{array}$ & $\begin{array}{l}\text { Medical, Healthcare and } \\
\text { Emergency Model } \\
\text { environments of complex } \\
\text { healthcare organizations }\end{array}$ \\
\hline
\end{tabular}

\section{RESEARCH METHODOLOGY}

The views of the position of an Electronic Clinic Record (ECR) vary broadly with lots of the stakeholder groups focusing on the provider requirements for knowledge management and information sharing. Usually lost in this focal point is the viewpoint and requirements of the patient in managing their medical condition and care. 


\subsection{The healthcare value system}

The healthcare policy makers will have to manage few ways in which to deliver more and more complex services to meet increasing demand and expectations for maintenance of health, treatment and care.

\subsection{Proposed Flow Diagram of Electronic Clinic Record}

While the increase of electronic adaptation of healthcare records, an enormous level of contractions have been used to indicate and classify the diverse variations of electronic healthcare records (EHCR). As below in Figure 1 we have shown proposed Electronic Clinic Record (ECR). First patient will arrive at clinic for online registration; from track number clinic will recognize the patient. After that patient will move to assessment and proved visit information such as clinical history, program notes, discharge summaries.

After assessment patient will move ahead to consultant and then patient will get cheek up by doctor. Then doctor will provide treatment to the patient then move to online payment system. If patient wants to go for further consultation then follow up all process and visit a specialist. As below figure 3 shows the detail flow diagram of proposed model.

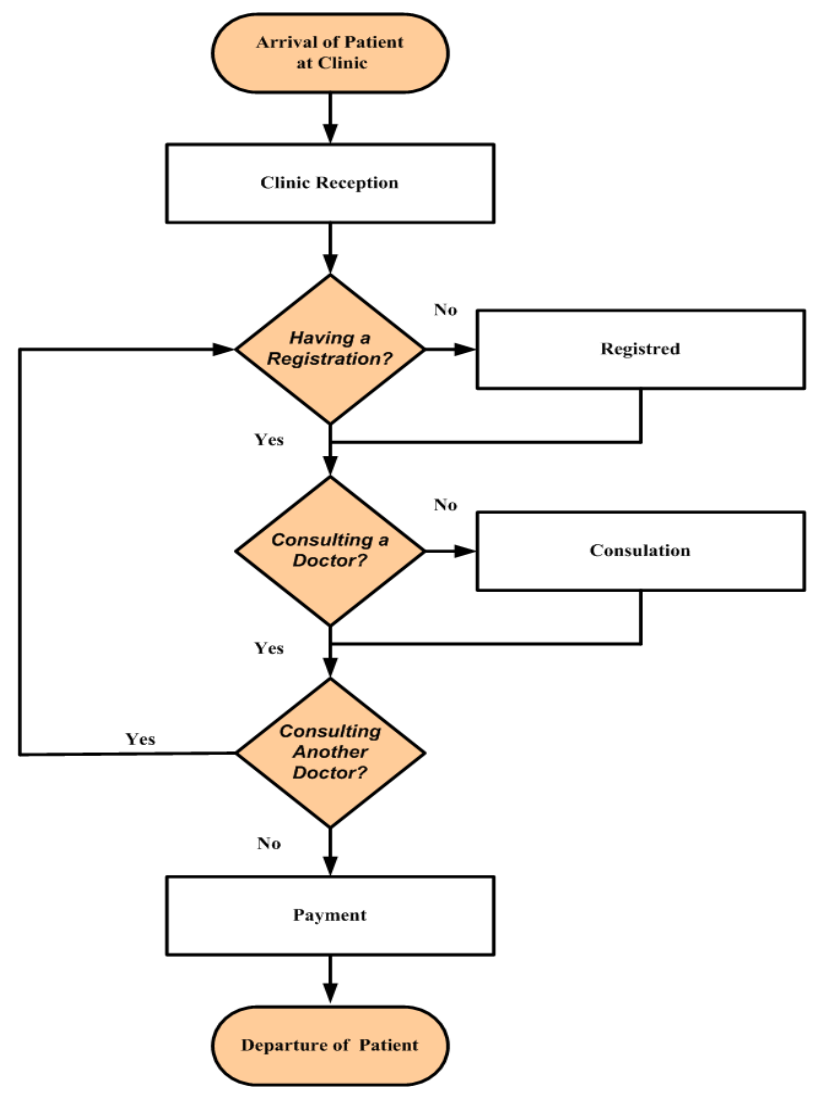

Figure 3. Flow Diagram of Electronic Clinical Record 
International Journal of Information Sciences and Techniques (IJIST) Vol.2, No.1, January 2012

\subsection{Steps of Proposed Model of Electronic Clinic Record Form.}

Proposed model of Electronic Clinic Record (ECR) form based on three steps such as patient information, patient reason for visit and treatment provided by clinic. First name as patient information and it takes personal information regarding patient such as patient track no as a primary key for anytime visit at clinic. This tracks no works as an identification of patient. This track no will provide all case history of patient. Furthermore, it's based on name of patient, age, gender, status, contract information and address. Figure 4 shows patient information form as following.

Patient Reason For Visit
\begin{tabular}{|ll|}
\hline To be filled by attending physician (Please mark () in the appropriate box) \\
[] Age (Infectious/viral) & [ ] Hypertension \\
[] Asthma & [] MVA/Injuries/Cut \\
[] Ear \& Eye Infection & [] URTI/Flu/Sore Throat/Tonsilitis \\
I] Abnormal PV Bleeding & [] Viral Fever/PU0 \\
I] Gastritis & [] UTI/Cistitis \\
[] Headache/Migraine & [] Sinusitis \\
[] S Skin Problem & [] Others (Pleases Specify) \\
\hline
\end{tabular}

Figure 4. Patient Information

Second step of proposed ECR is patient reason for visit at clinic. This information to be filled by attending physician depends on patient disease in clinic. In this list, already mention all basic diseases information, so doctor can diagnose and takes decision in a well manner. Figure 5 shows as following.

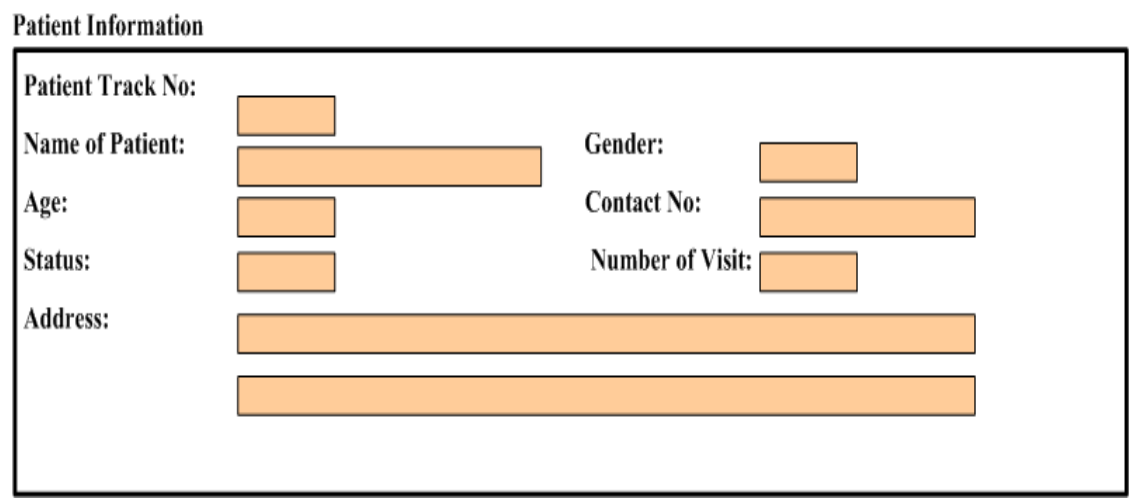

Figure 5. Patient Reasons for Visit

Third step of proposed ECR is treatment provided by clinic. It's an important part of ECR because consultation and medication prescription inside treatment provided by clinic. Also, detailed information about clinic expanses. 
International Journal of Information Sciences and Techniques (IJIST) Vol.2, No.1, January 2012

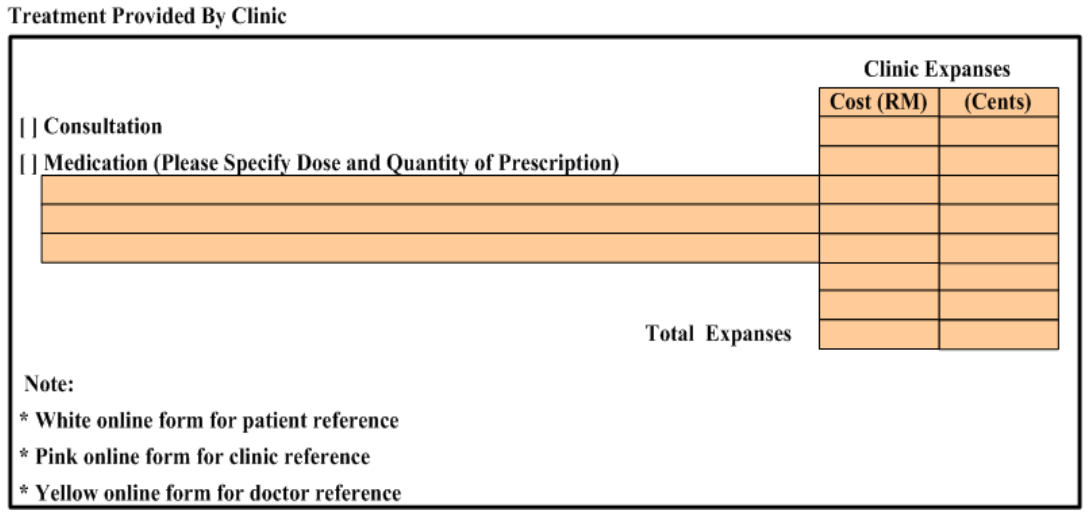

Figure 6. Treatment Provided to Patient by Clinic

\section{SURVEY AND ANALYSIS}

Survey and analysis based on 9 steps such as patient id, patient demographics, physician notes, nursing assessment, medication list, discharge summaries, laboratory tests and finally on tracking pharmaceuticals. Please respond to all questions checking only one item per question or noting your response in the text box provided.

Table 2. Survey on ECR

\begin{tabular}{|c|l|l|l|l|l|l|}
\hline $\begin{array}{c}\text { S. } \\
\text { No }\end{array}$ & \multicolumn{1}{|c|}{$\begin{array}{c}\text { Clinic } \\
\text { Documentation }\end{array}$} & $\begin{array}{c}\text { Implem } \\
\text { ented in } \\
\text { all units }\end{array}$ & $\begin{array}{c}\text { Implement } \\
\text { ed in at } \\
\text { least one } \\
\text { unit }\end{array}$ & $\begin{array}{c}\text { Starting to } \\
\text { Implement } \\
\text { in at least } \\
\text { one unit }\end{array}$ & $\begin{array}{c}\text { Considering } \\
\text { to } \\
\text { Implementing }\end{array}$ & $\begin{array}{c}\text { Do not have } \\
\text { Resources to } \\
\text { Implement }\end{array}$ \\
\hline 1 & Patient ID & & & & & \\
\hline 2 & $\begin{array}{l}\text { Patient } \\
\text { Demographics }\end{array}$ & & & & & \\
\hline 3 & Physician Notes & & & & & \\
\hline 4 & $\begin{array}{l}\text { Nursing } \\
\text { Assessments }\end{array}$ & & & & & \\
\hline 5 & Medication list & & & & & \\
\hline 6 & $\begin{array}{l}\text { Discharge } \\
\text { Summaries }\end{array}$ & & & & & \\
\hline 7 & Laboratory Tests & & & & & \\
\hline 8 & $\begin{array}{l}\text { Tracking } \\
\text { Pharmaceuticals }\end{array}$ & & & & & \\
\hline 9 & $\begin{array}{l}\text { Pharmaceutical } \\
\text { Administration }\end{array}$ & & & & & \\
\hline
\end{tabular}


International Journal of Information Sciences and Techniques (IJIST) Vol.2, No.1, January 2012

\section{CONCLUSIONS AND FINDING}

The finding of this research is to propose a new model that supports the Electronic Clinic Record (ECR) application. It will study essential related work to examine the available healthcare records outcome and drawbacks. It will propose new model to improve the clinical systems. The objective of this research is to ensure sufficient in-depth knowledge of the challenges confronting service delivery in health, especially in the healthcare sector; and a grasp of how the underlying ICT infrastructure and an ECR might be expected to assist in meeting these challenges.

\section{REFERENCES}

[1] E. Wilson and NK. Lankton. "Interdisciplinary Research and Publication Opportunities in Information Systems and Healthcare," Communication of the Association for Information Systems, Vol. 14, pp. 332-343, 2004

[2] I.C. Chang, H. G. Hwang, \& J.W. Lian, " Critical factors for adopting PACS in Taiwan: Views of radiology department directors,” Decision Support Systems, Vol. 42, pp. 1042-1053, 2005.

[3] R. Haux, E. Ammenwerth, W. Herzog, and P. Knaup, "Health care in the information society. a prognosis for the year 2013," Int J Med Inf, Vol. 66(1-3), pp. 3-21, 2002

[4] B. Wigertz, "Computer-based Patient Records. In Yearbook of Medical Informatics," Stuttgart: Schattauer Verlagsgesellschaft mbH, pp. 259-261, 2001.

[5] N. Boulus, "Managing the Gradual Transition from Paper to Electronic Patient Record (EPR)," Cand Scient Thesis, Department of Informatics, University of Oslo, Oslo, Norway, 30, April. 2004.

[6] K. Leonard, and W. Winkelman, "Developing electronic patient records: employing interactive methods to ensure patient involvement," Proceedings of the 28th Meeting of the European Working Group on Operational Research Applied to Health Services (ORAHS), Toronto, Canada, pp. 241-255, 28, August, 2002.

[7] B. Niclolson, "A Delphi Study Assessing Long-Term Access to Electronic Medical Records (EMR)," Master Thesis, Department of Systems and Engineering Management, Air University, Ohio, USA, March. 2008.

[8] M. Collen, “A History of Medical Informatics in the United States, 1950-1990," American Medical Informatics Association, Washington, D.C.USA, pp. 1-498, August. 1995.

[9] T. Naing, Y. Zainuddin, and S. Zailani, "Determinants of Information System Adoptions in Private Hospitals in Malaysia," 3rd International Conference on information and Communication Technologies: From Theory to Applications, Kuala Lumpur,Penang, Malaysia, pp. 1-2, 23, May. 2008.

[10] D. F. Sittig, B. L. Hazlehurst, T. Palen, \& J. Hsu, "A clinical information system research landscape,” The Permanente Journal, Vol. 6(2), pp. 62-68, 2002.

[11] J. Mendue, and C. Gaston, "Better Choices Better Health," Final Report of the South Australian Generational Health Review, Australia pp. 1-283, April. 2003.

[12] D. Johnston, "South Australian Health Information Management \& Technology, Strategy 20062010," South Australian Government, Adelaide, Australia, 2010.

[13] J. Van, W. Moorman, and A. Musen, "Electronic patient records in medical practice: a multidisciplinary endeavour”. Methods Inf Med, Vol. 38, No.4-5, pp. 287-288, 1999. 
International Journal of Information Sciences and Techniques (IJIST) Vol.2, No.1, January 2012

[14] A. Jerant and D. Hill, "Does the use of electronic medical records improve surrogate patient outcomes in outpatient settings?," Journal of Family Practice, Vol. 49, pp. 349-357. 2000.

[15] S. Tee, "Using Emergency Re-admission Time Window to Design the Re-admission Prediction Feature in Electronic Medical Record (EMR) Systems," IEEE Symposium on Computers \& Informatics, Cyberjaya, Malaysia, Vol. 2, No. 5, pp. 707-710, 01, August. 2011.

[16] MITRE, "Electronic Health Records Overview," National Institutes of Health National Center for Research Resources, MITRE, Centre for Enterprise Modernization McLean, Virginia, USA, pp. 1-30. April 2006.

[17] A. Koppar, and V. Sridhar, "A Workflow Solution for Electronic Health Records to Improve Healthcare Delivery Efficiency in Rural India," International Conference on eHealth, Telemedicine, and Social Medicine, Karnataka, India, pp. 227-232, 13, February. 2009.

[18] H. Mohd, and S. Mohamad, "Acceptance Model of Electronic Medical Record," Journal of Advancing Information and Management Studies, Malaysia, Vol. 2, No. 1, June, 2005.

[19] S. Hameed, A. Hashim, S. Sharifudeen, V. Meho, and O. Khalifa, "An Efficient Emergency, Healthcare, and Medical Information System," International Journals of Biometric and Bioinformatics (IJBB),Kuala Lumpur, Malaysia, Vol. 2, No. 5, pp. 1-9, 01, August. 2011.

[20] M. Hamidfar, “Adoption of Electronic Patient Records' by Iranian Hospitals' Staff," Department of Business Administration and Social Sciencs, Dividion of Industrial Marketing and e-commerce, Master Thesis, Lulea University of Technology, Norway, pp. 1-117, 2008.

[21] What are the Advantages of Electronic Medical Records Available from: http://www.wisegeek.com/what-are-the-advantages-of-electronic-medica records.htm, 6, May. 2010.

[22] D. F. Davis, "Perceived usefulness, perceived ease of use and user acceptance of information technology," MIS Quarterly, Vol. 13(3), pp. 319-340, 1989. 